\title{
(2) OPEN ACCESS \\ Perceived hazardous physical work environments and job-related affective well-being of navy officers aboard the Republic of Korea Navy ships and submarines in South Korea
}

\author{
Doseon Jo, ${ }^{1}$ C K Koh ${ }^{2}$
}

\begin{abstract}
- Additional material is published online only. To view, please visit the journal online (http://dx.doi.org/10.1136/ bmjmilitary-2020-001702).

1 Division of Clinical Nursing, Korea Armed Forces Nursing Academy, Daejeon, Republic of Korea

${ }^{2}$ College of Nursing, The Research Institute of Nursing Science, Seoul National University, Seoul, Republic of Korea
\end{abstract}

Correspondence to Associate Professor C K Koh, College of Nursing, Seoul National University, Seoul 03080, Republic of Korea; ckoh@snu.ac.kr

Received 26 October 2020 Revised 12 January 2021 Accepted 21 January 2021

Check for updates

(c) Author(s) (or their employer(s)) 2021. Re-use permitted under CC BY-NC. No commercial re-use. See rights and permissions. Published by BMJ.

To cite: Jo D, Koh CK. BMJ Mil Health Epub ahead of print: [please include Day Month Year]. doi:10.1136/ bmimilitary-2020-001702

\begin{abstract}
Introduction Navy ships and submarines are important military measures that protect the Republic of Korea. They also comprise naval officers' workplace. However, few studies have examined naval officers' working environment and their job-related well-being. This study aimed to explore exposure to hazardous work environments among navy officers aboard ships and submarines and their association with job-related affective well-being.
\end{abstract}

Methods This was a cross-sectional descriptive study. The sample comprised 146 officers from 4 navy ships and 98 officers from 5 submarines. Items of exposure to the eight types of hazardous work environments and the Jobrelated Affective Well-being Scale (JAWS) were included in the self-report survey questionnaires.

Results The most common hazards reported by officers aboard navy ships were vibration (63.7\%) and air pollution (56.2\%). For submarine officers, these hazards were lack of personal space (72.4\%) and air pollution (67.3\%). The average JAWS score for ship officers and submarine officers was $69.81(S D=10.89)$ and $70.50(S D=10.83)$, respectively. For ship officers, exposure to air pollution, noise, vibration, thermal discomfort during summer or winter and lack of personal space were significantly correlated with lower JAWS scores. For submarine officers, exposure to fire, burning or electrical shock, air pollution, noise, thermal discomfort during summer or winter and lack of personal space were significantly correlated with lower JAWS scores.

Conclusions This study revealed that some naval officers aboard ships or submarines are exposed to hazardous work environments. Moreover, certain types of hazardous work environments were associated with naval officers' job-related affective well-being.

\section{INTRODUCTION}

The Republic of Korea Navy (ROK Navy) has about 70000 personnel and possesses high-tech ships and submarines. It has a relatively high proportion of officers compared with other divisions because ships and submarines with advanced technology require special operation capabilities. For example, all submarine crews are commissioned or noncommissioned officers, and there is no seaman or civilian employee. Moreover, the officers comprise $60 \%$ of ship personnel. Seamen are all conscript selected from those applying to the Navy and serving compulsory military duty for about 20 months. Compared with seamen, all officers are employees

\section{Key messages}

- This study examined the hazardous work environments of navy ship and submarine officers and their job-related affective well-being.

- The results show that some naval officers aboard ships or submarines are exposed to hazardous work environments.

- Moreover, certain types of hazardous work environments were associated with naval officers' job-related affective well-being.

- This study is meaningful because it is the first to research the occupational hazards aboard South Korean navy ships and submarines with job-related affective well-being.

of the ROK Navy and their naval services are their full time job. Nevertheless, majority of the research on South Korean navy personnel's health is focused on seamen's stress, health behaviours and physical and mental health. ${ }^{12}$ However, few studies have focused on naval officers' health in the workplace.

Work hazard is a type of job stressor. Navy personnel may be exposed to physical work hazards, such as noise, whole-body vibration and toxic chemicals, specific to working aboard ships and the exposure rate to some physical hazards is high. For example, a study found that $74.3 \%$ of Royal Norwegian Navy personnel reported exposure to noise and $49.9 \%$ to vibration. ${ }^{3}$ Studies have found that the work environment aboard ships and submarines of the ROK Navy may have various hazards such as noise, vibration and limited personal space. ${ }^{14-6}$ However, no study has investigated the prevalence of hazards perceived by the people on board.

Affective well-being refers to 'the frequency and intensity of positive and negative emotions and mood'? (p. 431) Having high affective well-being indicates presence of positive affect, such as happiness, contentment and excitement, and absence of negative affect, such as sadness, anxiety and anger, and has been studied in military personnel. Clark et al examined affective well-being in military personnel and their family concerning the effect of deployment. ${ }^{8}$ Job-related affective well-being refers to emotional states or feelings associated with the work environment. ${ }^{9}$ It indicates the affective 
responses to job stressors and, thus, is an important facet for employees' occupational health. Therefore, job-related affective well-being and its associated work environments have been studied in people employed in various types of jobs. ${ }^{10} 11$ Nevertheless, there is a dearth of information regarding job-related affective well-being in navy personnel.

The work environment of ROK navy officers and their workplace well-being have rarely been studied. Moreover, no research has examined the work conditions and the job-related emotional health of navy officers. While some studies have revealed the significant associations between exposure to work hazards and job-related affect, ${ }^{10} 12$ no study has examined this relationship in military personnel. Therefore, this study aimed to explore the exposure to physical work hazards in navy personnel and the correlation with job-related affective well-being.

\section{METHODS}

Study design and procedure

A cross-sectional study was conducted using a self-report survey. The sample was selected based on a stratified two-stage cluster sampling approach where the strata was ship or submarine and where the first stage unit was squadron and the second stage unit battalion. A total of 330 officers in four ships and 122 officers in five submarines were considered for the selected battalions. Among these officers, 152 (46\%) ship officers and 99 (81\%) submarine officers responded to the survey questionnaires. After excluding the incomplete responses, 146 ship officers and 98 submarine officers were included in the study sample. To decrease under-reporting and over-reporting in the self-report survey, subjects were informed of how privacy was protected and confidentiality maintained during the informed consent procedure. A researcher of this study visited the battalions and distributed the questionnaires to the officers with an explanation about the survey; however, in ships and submarines, where visiting was not allowed at the time of the survey, a person in charge was instructed on the survey procedure and ethical issues. The individual survey questionnaires, which had been completed using a paper-and-pencil self-administered method, were put in a sealed envelope to return to the researcher. Data were collected in September 2017.

\section{Measurements}

Eight types of hazardous work environments were included in the survey: toxic chemicals, dangerous tools, fire, air pollution, noise, vibration, thermal discomfort and lack of personal space. These eight types of hazardous environments were selected using the following procedures. First, we reviewed items from the Korea National Health and Nutrition Examination Survey (KNHANES), ${ }^{13}$ a national survey performed every year since 1998 by the Ministry of Health and Welfare on a random sample of 10000 South Korean citizens. This survey provides nationally representative health data of the South Korean population. Therefore, by using items of this national survey, the results could be interpreted compared with the representative data of the South Korean population. Moreover, the validity and reliability of the KNHANES had been confirmed. ${ }^{13}$ Of the 500 health indicators used in the KNHANES, the five items related to hazardous work environments were included in this study: toxic chemicals, dangerous tools, fire, air pollution and noise. Second, we added three types of work hazards, vibration, ${ }^{45}$ thermal discomfort ${ }^{114}$ and lack of personal space, ${ }^{615}$ based on a literature review on work environments of ships and submarines. The question from the KNHANES that we used was "Are you exposed to each of the following work environments at work?" The items were the following: (i) 'toxic chemicals such as organic solvents, heavy metals or other chemicals'; (ii) 'dangerous tools, equipment or machinery'; (iii) 'fire, burning or electrical shock'; (iv) 'air pollution such as dust, gas, fume and lack of ventilation'; (v) 'noise'; (vi) 'thermal discomfort during summer and winter' and (vii) 'lack of personal space for privacy'. The responses were exposed or not exposed. Face validity was assessed prior to the study.

Job-related emotional health was assessed using the short form of the Job-Related Affective Well-Being Scale (JAWS), which was originally developed by Van Katwyk et al to assess emotional reactions to job stressors. ${ }^{8}$ Internal consistency reliability and nomological validity were assessed by Van Katwyk et al. ${ }^{8}$ Cronbach's alphas of the short form of JAWS for positive affect was 0.90 , and that for negative affect was $0.88 .^{11}$ This scale has been used for workers with diverse occupations and has been translated into different languages, including Polish, Dutch, Finish, German and Korean. ${ }^{11} 12$ The Korean version was used for Korean taxi drivers after the translation and back translation procedure and Cronbach's alphas of that study were 0.81 for positive affect and 0.92 for negative affect. ${ }^{12}$ The scale included 20 items pertaining to the participants' mood regarding their jobs. Ten items pertained to positive affect and 10 to negative affect. An example item for positive affect was "My job made me feel at ease" and an example for negative affect was "My job made me feel angry". 11 The question was "Please check one response for each item that best indicates how often you've experienced each emotion at work over the past 30 days". The answers ranged from 1 (never) to 5 (extremely often). Possible total scores ranged from 20 to 100 . Higher scores indicated better emotional health. Cronbach's alpha in the current study for positive affect and negative affect were 0.89 and 0.92 . Face validity was assessed prior to the survey.

\section{Data analysis}

SPSS/WIN V.23.0 program was used. A point-biserial correlation analysis was used to evaluate the relationship between each hazardous work environment and JAWS score. This analysis was selected because there was no clear evidence to support a dependency or causal relation between these two variables. Exposure to each hazardous environment was coded as 1 while not-exposure was coded as 0 . In terms of missing values, there were no missing values for the work hazard items and the missing values of JAWS were replaced by the mean score of JAWS of the subject.

\section{RESULTS}

\section{Participant characteristics}

The mean age for ship officers was 30.70, with a median of 29 years, and that for submarine officers was 29.61, with a median of 27 years (Table 1). There were six $(2.5 \%)$ female ship officers, while there were no female submarine officers. The average service duration was 12.96 and 17.66 months for ship officers and submarine officers, respectively.

\section{Hazardous work environment}

The most common hazardous work environments reported by ship officers were vibration (63.7\%), air pollution (56.2\%), lack of personal space $(54.8 \%)$ and noise $(54.8 \%)$ (Table 2$)$. The most common hazards reported by submarine officers were lack of personal space $(72.4 \%)$, air pollution $(67.3 \%)$ and dangerous tools, equipment or machinery (45.9\%). The rates of exposure to three types of hazards-vibration, thermal discomfort during 
Table 1 General participant characteristics

\begin{tabular}{|c|c|c|c|}
\hline & $\begin{array}{l}\text { Ships } \\
(\mathrm{n}=146)\end{array}$ & $\begin{array}{l}\text { Submarines } \\
(n=98)\end{array}$ & $\begin{array}{l}\text { Total } \\
(\mathrm{n}=244)\end{array}$ \\
\hline & $\begin{array}{l}\text { Mean (SD)/ } \\
\text { Median (range) }\end{array}$ & $\begin{array}{l}\text { Mean (SD)/Median } \\
\text { (range) }\end{array}$ & $\begin{array}{l}\text { Mean (SD)/ } \\
\text { Median (range) }\end{array}$ \\
\hline \multirow[t]{2}{*}{ Age (years) } & $\begin{array}{l}30.70(8.16) / 29 \\
(19-48)\end{array}$ & $\begin{array}{l}29.61(6.92) / 27 \\
(21-46)\end{array}$ & $\begin{array}{l}30.26(7.69) / 29 \\
(19-48)\end{array}$ \\
\hline & Frequency (\%) & Frequency (\%) & Frequency (\%) \\
\hline \multicolumn{4}{|l|}{ Sex } \\
\hline Men & 140 (95.9\%) & 238 (97.5\%) & $238(97.5 \%)$ \\
\hline Women & $6(4.1 \%)$ & $6(2.5 \%)$ & $6(2.5 \%)$ \\
\hline \multicolumn{4}{|l|}{ Marital status } \\
\hline Single & 79 (54.1\%) & 134 (54.9\%) & 134 (54.9\%) \\
\hline Married & 67 (45.9\%) & $110(45.1 \%)$ & $110(45.1 \%)$ \\
\hline \multicolumn{4}{|l|}{ Religion } \\
\hline No religion & 79 (54.1\%) & 46 (46.9\%) & $125(51.2 \%)$ \\
\hline Having religion & $67(45.9 \%)$ & $52(53.1 \%)$ & $119(48.8 \%)$ \\
\hline $\begin{array}{l}\text { Duration of service } \\
\text { (months) }\end{array}$ & $12.96(9.77)$ & $17.66(15.45)$ & $14.85(12.56)$ \\
\hline \multicolumn{4}{|c|}{ Over work hours ( $>40$ hours/week) } \\
\hline No over work hours & $104(71.2 \%)$ & $51(52 \%)$ & $155(63.5 \%)$ \\
\hline Over work hours & $42(28.8 \%)$ & $47(48 \%)$ & $89(36.5 \%)$ \\
\hline
\end{tabular}

summer or winter and lack of personal space-differed significantly between the two groups.

Job-related affective well-being

The average JAWS score for ship officers was $69.81(\mathrm{SD}=10.89)$, while that for submarine officers was $70.50(S D=10.83)$. There

Table 2 Perceived hazardous work environment

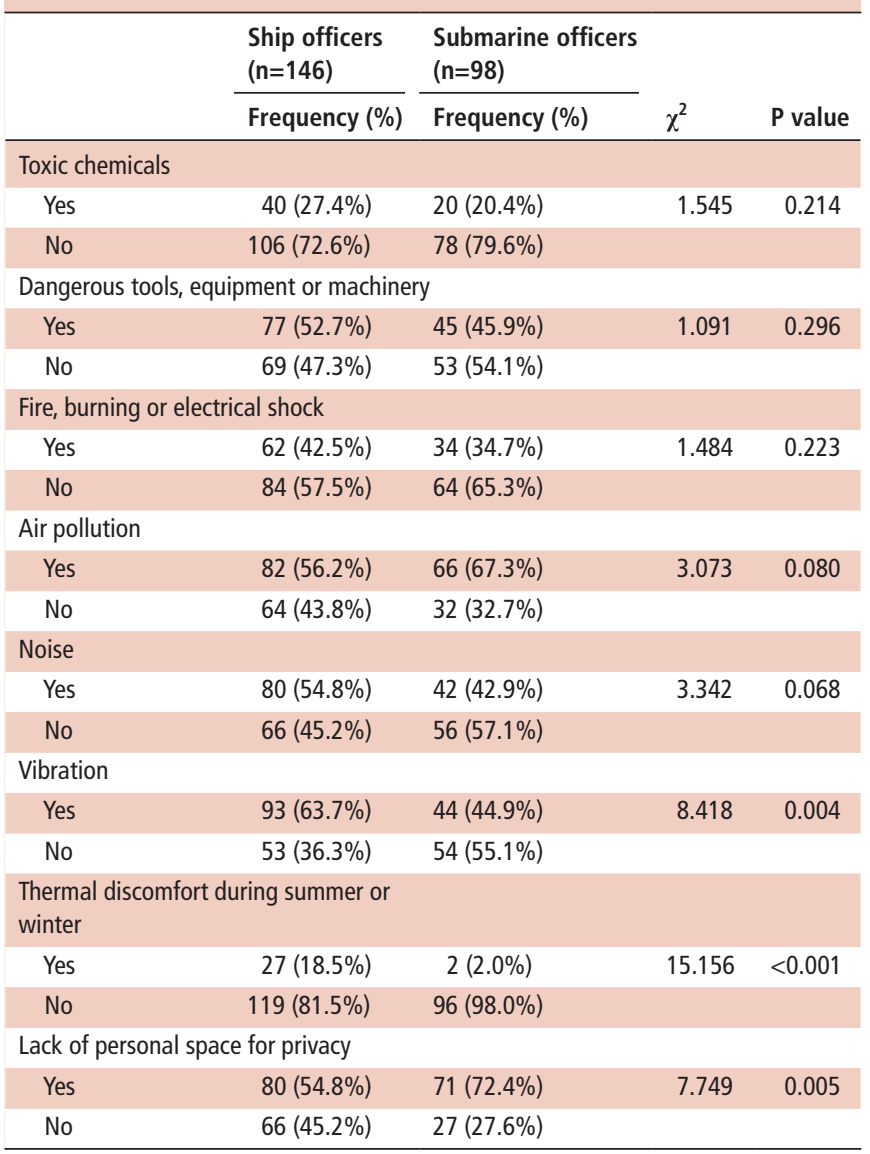

Table 3 Correlations between hazardous environments and jobrelated affective well-being

\begin{tabular}{|c|c|c|c|c|}
\hline \multirow[b]{2}{*}{ Hazardous environments } & \multicolumn{2}{|c|}{$\begin{array}{l}\text { Ship officers } \\
(n=146)\end{array}$} & \multicolumn{2}{|c|}{$\begin{array}{l}\text { Submarine officers } \\
(\mathrm{n}=98)\end{array}$} \\
\hline & $r_{p b}$ & $P$ value & $r_{p b}$ & $P$ value \\
\hline Toxic chemicals & -0.123 & 0.141 & -0.350 & $<0.001$ \\
\hline Dangerous tools, equipment or machinery & -0.134 & 0.108 & -0.052 & 0.609 \\
\hline Fire, burning or electrical shock & -0.158 & 0.057 & -0.225 & 0.026 \\
\hline Air pollution & -0.170 & 0.040 & -0.269 & 0.008 \\
\hline Noise & -0.242 & 0.003 & -0.234 & 0.020 \\
\hline Vibration & -0.303 & $<0.001$ & -0.191 & 0.059 \\
\hline $\begin{array}{l}\text { Thermal discomfort during summer or } \\
\text { winter }\end{array}$ & -0.258 & 0.002 & -0.208 & 0.040 \\
\hline Lack of personal space for privacy & -0.274 & 0.001 & -0.245 & 0.015 \\
\hline
\end{tabular}

was no significant difference in JAWS score between submarine and ship officers. Moreover, the correlation analysis between each sociodemographic (age, sex, marital status and religion) and work-related characteristics (duration of service and overtime work) of the officers and JAWS scores revealed no significant association for ship officers or submarine officers.

\section{Correlation between hazardous work environments and job-} related affective well-being

For ship officers, exposure to air pollution, noise, vibration, thermal discomfort during summer or winter and lack of personal space were significantly correlated with lower JAWS scores (Table 3). For submarine officers, exposure to fire, burning or electrical shock, air pollution, noise, thermal discomfort during summer or winter and lack of personal space were significantly correlated with lower JAWS scores.

\section{DISCUSSION}

This study explored hazardous work environments perceived by naval officers working aboard ships and submarines in South Korea and examined their association with job-related affective well-being. The results showed that certain percentages of South Korean naval personnel experienced various work hazards, some of which were associated with their job-related affective well-being.

Vibration was one of the most frequently reported work hazards by crews working on ships. In this study, 63.7\% of ship personnel reported exposure to vibration, while this figure stood at $44.9 \%$ among submarine personnel. These results reflect a study on the Royal Norwegian Navy, which revealed that $49.9 \%$ of the navy personnel reported exposure to vibration, ${ }^{3}$ while they are higher than the national data of South Korean workers, where $23.5 \%$ of workers nationwide were exposed to vibration. ${ }^{16}$ Moreover, a considerable number of navy personnel are exposed to noise. Noise exposure was reported by $54.8 \%$ of ship personnel and $42.9 \%$ of submarine personnel; these figures are also high compared with those in the KNHANES data, whose rate of noise exposure was 34.2\%. ${ }^{17}$ However, Moen et al reported that $74.3 \%$ of employees of the Royal Norwegian Navy experienced levels of noise exposure ranging from some to very much. ${ }^{3}$

It was also reported that continuous exposure to noise increased the risk of noise-induced hearing loss in military personnel. ${ }^{18}$ Nevertheless, the levels of noise have been reported to exceed the criteria for South Korean ships. ${ }^{45}$ A study revealed that the overall noise level in the residency areas of the crew of a 665-ton naval supply ship was $78 \mathrm{~dB}$, exceeding the 60 
$\mathrm{dB}$ limit for sleep disturbance and the $70 \mathrm{~dB}$ limit for decrease concentration. ${ }^{4}$

Exposure to particulate air pollution or poor indoor air quality in the worksite is a hazard that needs to be controlled to maintain occupational health. ${ }^{19}$ In this study, $67.3 \%$ of submarine personnel and $56.2 \%$ of ship personnel reported poor air quality. Jo et al measured the air pollution of South Korean coastal patrol ships of various sizes and reported that the carbon dioxide levels of all the examined areas exceeded the environmental standard of $1000 \mathrm{ppm}$, which seemed to be induced by a lack of air supply from the outside. ${ }^{20}$ In their study, the levels of sulfur dioxide and formaldehyde were also higher than the environmental standards.

Inadequate space for work and break could be one of the stress factors affecting occupational health. ${ }^{21}$ Lack of personal space was the most frequently reported hazard by submarine personnel and the fourth-most frequently reported hazard by ship personnel. The limited space aboard submarines does not afford privacy in their bunks. Moreover, submariners work and live in a confined and isolated space while on duty, which creates an extreme work environment. ${ }^{15}$ According to a report in South Korea, residential space per person in Navy submarines is just $3.9 \mathrm{~m}^{2}{ }^{6}$ Regarding navy ships, crew members experience difficulty in finding sufficient personal and private space.

Thermal discomfort is another of the hazardous work environments. ${ }^{22}$ In this study, thermal discomfort during summer or winter occurred in $18.5 \%$ of ship officers and just $2.0 \%$ of submarine officers. Ship crews are often exposed to hot and cold temperature during door watch duty or work on deck. ${ }^{14}$

Exposure to toxic chemicals, including organic solvents and heavy metals, was reported by $27.4 \%$ of ship officers and $20.4 \%$ of submarine officers. Moreover, exposure to fire, burning or electrical shock was reported by $42.5 \%$ of ship officers and $34.7 \%$ of submarine officers. According to the KNHANES, just $16.4 \%$ of the Korean population were exposed to toxic chemicals at work and $15.5 \%$ to fire, burning or electrical shock. ${ }^{17}$ Compared with this national data, ship and submarine naval officers seem to be more exposed to toxic chemicals and fire, burning or electrical shock.

With regard to the JAW, the average JAWS scores were 69.81 $(S D=10.89)$ for ship officers and $70.50(S D=10.83)$ for submarine officers, which are lower than the score of 99.8 for office workers in the USA and higher than the score of 54.5 for taxi drivers in South Korea. ${ }^{12} 23$ In this study, for ship officers, exposure to air pollution, vibration, noise, thermal discomfort during summer or winter and lack of personal space were associated with lower affective well-being. For submarine officers, exposure to toxic chemicals, fire, burn or electric shock, air pollution, thermal discomfort during summer or winter and lack of personal space were associated with lower affective well-being.

Furthermore, the association between physical or ergonomic hazards and mental health has been reported. Zeng et al revealed that exposure to work hazards such as noise and toxic chemicals was significantly associated with lower levels of psychological well-being among workers. ${ }^{24}$ This study is the first to support the relationship between physical work hazards and affective health among navy personnel.

This study has the following limitations. First, this study used the self-report survey method. There might be self-reporting bias, such as social desirability bias and recall bias. Second, this study examined the correlations between different types of hazardous environments and affective well-being without considering which one is independent and dependent. Moreover, the confounding variables of this relationship were not evaluated; therefore, the mechanisms underlying this association remain unclear. Further research is also required to consider multiple factors, including organisational work environments, to understand navy personnel's job-related affective well-being. Third, in the current study, chemicals were not examined separately. Studies need to be performed to explore the individual exposure rates of the various types of toxic chemicals, such as asbestos, organic solvents, petrol and lead, aboard ships and submarines because each chemical has very different levels of dangers and harm. Forth, this study assessed individual perceptions through self-reported measures. Further research must include data obtained using objective exposure measurement techniques and develop methods to reduce the exposures on navy ships and submarines. Fifth, although the sample was selected with a stratified two-stage cluster random sampling procedure, the small sample size might affect the generalisability of the study. Studies with larger samples need to be performed. Furthermore, this study only included a small number of female officers. There were no female submarine officer because ROK naval submarines do not allow women on board. In this study, only $2.5 \%$ of ship officers were women. The exact number of female officers on board ships in the ROK Navy has not been reported. Further study is needed to focus on female naval officers on board naval ships. Women in the military may have different psychological well-being experiences. ${ }^{25}$ Finally, this study only included officers and did not include lower-ranking seamen. There are no seamen in the ROK submarines, but further study is needed to focus on lower-ranking seamen on board navy ships. They may have different work-related health issues than officers.

\section{CONCLUSIONS}

Ships and submarines are central to the work and lives of naval officers. This study revealed that some naval officers aboard ships or submarines are exposed to hazardous work environments. Moreover, certain types of hazardous work environments were associated with naval officers' job-related affective well-being. The ROK naval ships and submarines are important military means to protect national security but, at the same time, they are the workplaces of South Korean naval officers who are employees of the ROK Armed Forces. Efforts should be devoted to reduce hazardous work environments and improve their occupational health.

Contributors DJ and CKK made substantial contributions to conception and design of the study. DJ conducted a survey and analysis of data. DJ and CKK wrote a draft of the article and have read and approved the manuscript. This work is derived from a master's thesis of Lieutenant Commander DJ (first author).

Funding The authors have not declared a specific grant for this research from any funding agency in the public, commercial or not-for-profit sectors.

Disclaimer The views expressed are solely those of the authors and do not reflect the official policy or position of the Republic of Korea Armed Forces, the Republic of Korea Navy or the Republic of Korea Government.

Competing interests None declared.

Patient consent for publication Not required.

Ethics approval The study was approved by the Institutional Review Board of the Armed Forces Medical Command. Participants who volunteered to participate completed the survey. Written informed consent was obtained from all participants. A security review process was conducted by the ROK Navy prior to the survey.

Provenance and peer review Not commissioned; externally peer reviewed. Data availability statement Data are available on reasonable request.

Open access This is an open access article distributed in accordance with the Creative Commons Attribution Non Commercial (CC BY-NC 4.0) license, which permits others to distribute, remix, adapt, build upon this work non-commercially, and license their derivative works on different terms, provided the original work is 
properly cited, appropriate credit is given, any changes made indicated, and the use is non-commercial. See: http://creativecommons.org/licenses/by-nc/4.0/.

\section{REFERENCES}

1 Kim YK, EG O. Health behavior and quality of life among Korean navy. Kor J Mil Nurs Res 2015;33:53-66.

2 Kang J, Jung S, Yoon Y. The relationships among depression level, stress, and perceived organizational support in Korean navy sailors. Korean J Mil Nurs Res 2011;29:66-76.

3 Moen BE, Koefoed VF, Bondevik K, et al. A survey of occupational health in the Royal Norvegian navy. Int Marit Health 2008:59:35-44.

4 Park MY, Han H, Cho H. Indoor noise analysis of naval combat service support boat. Trans Korean Soc Noise Vib Eng 2011;7:609-14.

5 Oh K. A study of health effect on noise and whole body vibration in the PKM Crew. J Korean Mil Med Assoc 2001;32:17-26.

6 Korea Joong Ang Daily. Navy officers avoid working at submarine. Available: https:// news.joins.com/article/23924447 [Accessed 21 Dec 2020].

7 Luhmann M, Hawkley LC, Eid M, et al. Time frames and the distinction between affective and cognitive well-being. J Res Pers 2012;46:431-41.

8 Van Katwyk PT, Fox S, Spector PE, et al. Using the Job-Related affective well-being scale (jaws) to investigate affective responses to work stressors. J Occup Health Psychol 2000;5:219-30.

9 Clark MA, O'Neal CW, Conley KM, et al. Resilient family processes, personal reintegration, and subjective well-being outcomes for military personnel and their family members. Am J Orthopsychiatry 2018;88:99-111.

10 Nixon AE, Lanz JJ, Manapragada A, et al. Nurse safety: how is safety climate related to affect and attitude? Work Stress 2015;29:401-19.

11 Van Katwyk PT, Fox S, Spector PE. Job-related affective well-being scale, jaws. Available: http://shell.cas.usf.edu/ pspector/scales/jawspage.html [Accessed 10 Dec 2020].

12 CM K, Koh CK. Workplace hazards, work environment, and physical-affective health of TAXI drivers. Korean J Occup Health Nurs 2010;19:246-57.

13 Korean National Institute of Health. The 2009 Korea National health and nutrition examination survey.. Available: http://www.mohw.go.kr/react/jb/sjb030301vw.jsp?
PAR_MENU_ID=03\&MENU_ID $=0321 \& C O N T$ SEQ $=264574 \&$ page $=1$ [Accessed 5 Dec 2019].

14 Lee H-H, Shin S, Lee J-Y. Design requirements by evaluating comfort while wearing Korean naval duty uniforms for summer and winter. KJCLS 2016;27:419-35.

15 Bae DS, Chae M. Study of the factors of a submarine crews' turnover intention based on Kano model and suggestion of the policy measures. J Korea Acad Industr Coop Soc; 15:4950-60.

$16 \mathrm{Kim}$ YS, Cho HH. First and second Korean working conditions survey: a comparison between South Korea and Eu countries. Korean I Occup Health Nurs 2014;23:277-86

17 Kim SH, Kim NS, Lee CG. The association of employment status, workplace environment, and hazard exposure with health outcome in the adult Korean population according to KNHANES IV. J Korean Soc Occup Environ Hyg 2013;23:229-42.

18 Luha A, Merisalu E, Reinvee M, et al. In-vehicle noise exposure among military personnel depending on type of vehicle, riding compartment and road surface. BMJ Mil Health 2020;166:214-20.

19 Pitarma R, Marques G, Ferreira BR. Monitoring indoor air quality for enhanced occupational health. J Med Syst 2017:41:23.

20 Jo H-J, Doe G-Y, Kim D-I, et al. Evaluation of environmental conditions on board in terms of air pollution and electromagnetic wave in coastal small-sized ships. J Navig Port Res 2002;26:555-61.

21 Saaranen T, Tossavainen $\mathrm{K}$, Turunen $\mathrm{H}$, et al. Occupational wellbeing in a school community - Staff's and occupational health nurses' evaluations. Teach Teach Educ 2006;22:740-52.

22 Malchaire J, Gebhardt HJ, Piette A. Strategy for evaluation and prevention of risk due to work in thermal environments. Ann Occup Hyg 1999;43:367-76.

23 Wilkerson GB, Boer NF, Smith CB, et al. Health-Related factors associated with the healthcare costs of office workers. J Occup Environ Med 2008;50:593-601.

24 Zeng Z, Guo Y, Lu L, et al. Mental health status and work environment among workers in small- and medium-sized enterprises in Guangdong, China-a cross-sectional survey. BMC Public Health 2014;14:1162.

25 Jones GL, Hanley T. The psychological health and well-being experiences of female military veterans: a systematic review of the qualitative literature. J R Army Med Corps 2017;163:311-8 